\title{
Community education status on knowledge for mosquito borne diseases (Malaria, Dengue, Chikungunya) in Indore city
}

\author{
Salil Sakalle ${ }^{1}$, A.K. Khatri ${ }^{2, *}$, Suraj Sirohi ${ }^{3}$, Sanjay Dixit ${ }^{4}$, Anubhuti Kujur ${ }^{5}$ \\ ${ }^{1}$ Professor, ${ }^{2}$ Associate Professor, ${ }^{3}$ Assistant Professor, ${ }^{4}$ Professor \& HOD, ${ }^{5}$ Resident Dept. of Community Medicine, M.G.M. \\ Medical College, Indore, Madhya Pradesh, India
}

*Corresponding Author:

Email: pandit.dhruv06@gmail.com

\begin{abstract}
Introduction: Vector borne disease like malaria dengue and Chikungunya are major public health problem in recent years

Objectives: To assess knowledge regarding breeding places of mosquito causing Malaria, dengue and chikungunia. To assess the Knowledge of people towards preventing Mosquito Borne Diseases (Malaria, Dengue, Chikungunya).

Materials and Method: A cross sectional observational community based study was carried out in different localities of Indore city. Simple random sampling technique was used to select 300 study participants of age group 18-65yr. Written Informed consent taken from the participants and pre designed, pre tested, semi structured questionnaire was used for elicit response from study participants. The data collected were analyzed and presented in table formats, charts which were obtained using excel and SPSS -22. Study duration was 6 Months. Relevant statistical test was applied and $\mathrm{p}$ value was calculated where ever required \& considered significant when it is $<0.05$

Results: Most of the population has been found to reside near stagnant water source, $73 \%$ the people either disagrees or doesn't know that fumigation occurs in their colony or not, $74 \%$ didn't have indoor residual spray in their houses, $54 \%$ clean their water tank within 1 month, $61 \%$ have crude knowledge about the symptoms of Malaria, Dengue and Chikungunya and they visit doctor for treatment.

Conclusion: Measures taken to prevent mosquito bite, Symptom knowledge, and Knowledge of suffering second time with dengue can be hazardous has significant association with the education status of study population.
\end{abstract}

Keywords: Community Education, Chikungunya, Dengue, Malaria.

\section{Introduction}

Vector-borne diseases (VBD), account for $17 \%$ of the estimated global burden of all infectious diseases. Their burden and economic impact continue to be very high. In the WHO South-East Asia Region, the VBD of public health importance are malaria, dengue, Japanese encephalitis, chikungunya, lymphatic filariasis and kala-azar. ${ }^{1}$ According to National Vector Borne Disease Control Programme, Annual Report 2014-15 Malaria continues to pose a major public health threat in different parts of the country, particularly due to Plasmodium falciparum due to which severity may develop and may cause fatality, if not treated early. About $91 \%$ of malaria cases and $99 \%$ of deaths due to malaria are reported from high disease burden states namely Northeastern (NE) States, Andhra Pradesh, Chhattisgarh, Gujarat, Jharkhand, Karnataka, Madhya Pradesh, Maharashtra, Orissa, Rajasthan and West Bengal. ${ }^{2}$

Dengue is endemic in 35 states/UTs. After 1996 outbreak (total 16517 cases and 545 deaths) upsurge of cases were recorded in 2003, 2005, 2008, 2010, 2012 and 2013. In 2010 total 28292 cases and 110 deaths have been reported. During 2012, 50222 cases and 242 deaths and during 2013, 75808 cases and 193 deaths were reported. ${ }^{2}$ As per NVBDCP 2108 cases and 8deaths in 2015 and 3150cases and 12deaths were reported by dengue in Madhya Pradesh. ${ }^{3}$
During 2006, total 1.39 million clinically suspected Chikungunya cases reported in the country. Out of 35 States/UTs, 16 were affected: Andhra Pradesh, Karnataka, Maharashtra, Tamil Nadu, Madhya Pradesh, Gujarat, Kerala, Andaman \& Nicobar Islands, Delhi, Rajasthan, Puducherry, Goa, Orissa, West Bengal, Lakshadweep and Uttar Pradesh. In 2008, 2009, 2010, 2011 and 2012 95091, 73288, 48176, 20402 and 15977 suspected Chikungunya fever cases with nil death were reported. During 2013, 18840 suspected Chikungunya cases were reported whereas during 2014 (till November) 12694 suspected Chikungunya cases have been reported. ${ }^{2}$

As per World Health Organization, Vector-borne diseases account for more than $17 \%$ of all infectious diseases, causing more than 700000 deaths annually. More than 3.9 billion people in over 128 countries are at risk of contracting dengue, with 96 million cases estimated per year. Malaria causes more than 400000 deaths every year globally, most of them children under 5 years of age. Many of these diseases are preventable through informed protective measures. ${ }^{3,4}$

Malaria, Dengue and Chikungunya are diseases for which mosquito is a vector and they are one of the major public health problems in India specially last two viral diseases.

The Global vector control response (GVCR) 20172030 approved by the World Health Assembly (2017) provides strategic guidance to countries and 
development partners for urgent strengthening of vector control as a fundamental approach to preventing disease and responding to outbreaks. To achieve this a realignment of vector control programmes is required, supported by increased technical capacity, improved infrastructure, strengthened monitoring and surveillance systems, and greater community mobilization. Ultimately, this will support implementation of a comprehensive approach to vector control that will enable the achievement of disease-specific national and global goals and contribute to achievement of the Sustainable Development Goals and Universal Health Coverage. ${ }^{4}$

Common predictors of correct knowledge about etiology and clinical features of malaria were male sex and college education. Female sex, illiteracy and tribal population were more likely to have been associated with wrong beliefs about fatality of malaria. Being tribal respondent was the single most important predictor of inadequate knowledge. ${ }^{5}$ Health education must be taken into account for communities in malaria endemic areas to produce desired outcomes in malaria control. $^{6}$

In Madhya Pradesh situation is not good recently we come to know that incidence of dengue, Chikungunya was increasing via various media we also confirm with local health authorities of Indore district. Indore is the business capital of Madhya Pradesh and it is important city of central India, recently Indore got cleanest city award for national authority. Even then the local population is suffering with vector born diseases. So it is essential to know the causes behind recent incidence increase of such diseases. Despite of extensive effort by various government organizations what are the reason for this situation and perception of general population regarding vector borne diseases, this study was aim to assess knowledge of people on mosquito breeding places and also towards preventing Mosquito Borne Diseases.

\section{Materials and Method}

A cross sectional observational community based study was carried out in different localities i.e. Marimata Square, Banganga, Durga Colony, Govind Colony, Raghuwanshi Colony, Vrindawan Colony, Vishal Nagar, Platinum Paradise Colony, Nand Bagh colony, Kamla Nehru of Indore city. Study duration was 6 Months form, 01 November 2017 - 01 May 2018. Simple random sampling technique using computer generated random number table was used to select 300 study participants of age group 18-65 year. Each colony had house number and building/ flat number. Investigator firstly collected total number of houses and flats available in particular colony with the help of Nagar Nigam office. From each of randomly selected house one member based on inclusion criteria was selected. Sample size was calculated on assumption that $25 \%$ of participants were aware of different preventing measures. Sample size was come out to be 285 with $5 \% \alpha$ error and $80 \%$ power with $95 \%$ confidence limit. This sample size was rounded as 300 . Written Informed consent taken from the participants and pre designed, pre tested, semi structured questionnaire was used for elicit response from study participants. The data collected were analyzed and presented in table formats, charts which were obtained using excel and SPSS -22 (statistical package for social science). Chi square test was applied and $\mathrm{p}$ value was calculated where ever required \& considered significant when it is $<0.05$.

\section{Results}

Table 1: Demographic profile of study participants

\begin{tabular}{|c|c|c|}
\hline \multicolumn{3}{|c|}{ Gender Distribution $(\mathrm{N}=300)$} \\
\hline & Frequency & Percentage \\
\hline Male & 142 & 47 \\
\hline Female & 158 & 53 \\
\hline \multicolumn{3}{|c|}{ Age Distribution $(\mathrm{N}=300)$} \\
\hline $18-25$ & 128 & 43 \\
\hline $26-30$ & 54 & 17 \\
\hline $31-35$ & 38 & 13 \\
\hline $36-40$ & 30 & 10 \\
\hline $41-45$ & 22 & 7 \\
\hline $46-50$ & 12 & 4 \\
\hline $51-55$ & 8 & 3 \\
\hline $56-60$ & 6 & 2 \\
\hline $61-65$ & 2 & 1 \\
\hline \multicolumn{3}{|c|}{ Number of Family Members $(\mathrm{N}=300)$} \\
\hline 2-4 Members & 78 & 26 \\
\hline 5-8 Members & 208 & 69 \\
\hline 9-12 Members & 14 & 5 \\
\hline \multicolumn{3}{|c|}{ Education Status $(\mathrm{N}=300)$} \\
\hline Till 10th class & 12 & 4 \\
\hline 11-12th class & 60 & 20 \\
\hline Graduate & 146 & 49 \\
\hline Post graduate & 82 & 27 \\
\hline
\end{tabular}

In present study out of total $300,47 \%$ were male and $53 \%$ were female most of them $(43 \%)$ belongs to age group 18-25yrs and $69 \%$ having family of 5-8 members , $76 \%$ participants were graduate and above.

Table 2: Response on previous exposure to Malaria, Dengue or Chikungunya

\begin{tabular}{|l|c|c|}
\hline $\begin{array}{c}\text { No. of people Suffered } \\
\text { from Malaria, Dengue } \\
\text { or Chikungunya }\end{array}$ & Frequency & Percentage \\
\hline Yes & 196 & 65 \\
\hline No & 104 & 35 \\
\hline Total & 300 & 100 \\
\hline
\end{tabular}

$65 \%$ of the Sample Population has suffered from Malaria, Dengue or Chikungunya in past. 
Table 3: Number of Households where sewage water gets collected $(\mathrm{N}=300)$

\begin{tabular}{|l|c|c|}
\hline $\begin{array}{l}\text { Presence of Stagnant } \\
\text { Water Source near House }\end{array}$ & Frequency & Percentage \\
\hline Yes & 144 & 48 \\
\hline No & 152 & 51 \\
\hline No response & 4 & 1 \\
\hline $\begin{array}{l}\text { Number of Households where sewage water gets } \\
\text { collected }\end{array}$ & 110 & 37 \\
\hline Yes & 190 & 63 \\
\hline No & 86 & 29 \\
\hline Distance of Sewage water collection from houses \\
\hline $10-50 \mathrm{~m}$ & 10 & 3 \\
\hline $51-100 \mathrm{~m}$ & 14 & 5 \\
\hline $200-500 \mathrm{~m}$ & 190 & 63 \\
\hline No Collection & & \\
\hline
\end{tabular}

$37 \%$ of sample population resides within $500 \mathrm{~m}$ range from sewage water collection. $48 \%$ of the sample population resides near stagnant water source.

Table 4: Response on Fumigation/residual spray $(\mathrm{N}=300)$

\begin{tabular}{|l|c|c|}
\hline $\begin{array}{c}\text { Fumigation in Colony by } \\
\text { Municipality }\end{array}$ & Frequency & Percentage \\
\hline Yes & 81 & 27 \\
\hline No & 171 & 57 \\
\hline Don't Know & 48 & 16 \\
\hline Residual Spray in houses & & \\
\hline Yes & 78 & 26 \\
\hline No & 200 & 66.67 \\
\hline Don't Know & 22 & 7.33 \\
\hline
\end{tabular}

Maximum (67\%) of study population didn't had indoor residual spray in their houses. $26 \%$ of study population had indoor residual spray in their houses

Table 5: Time of most Mosquito Bites Experienced and personal Measures taken by individuals to prevent Mosquito bite (Multiple responses)

\begin{tabular}{|l|c|}
\hline \multicolumn{1}{|c|}{ Most Mosquito Bites Experienced } & Percentage \\
\hline Early Morning & 1 \\
\hline Day & 5 \\
\hline Night & 54 \\
\hline Evening & 43 \\
\hline $\begin{array}{l}\text { Measures taken by individuals to prevent } \\
\text { Mosquito bite }\end{array}$ & \\
\hline Vaporizer & 15 \\
\hline Cream & 14 \\
\hline Coil & 31 \\
\hline Bed Nets & 37 \\
\hline Screening of Windows and Doors & 29 \\
\hline Neem Leaves Burning & 2 \\
\hline Aerosol Spraying & 28 \\
\hline No Measures taken & 3 \\
\hline Type of Clothes Worn at Home & 3 \\
\hline Full Sleeves & 45 \\
\hline Half Sleeves & 11 \\
\hline Sleeveless & 10 \\
\hline Shorts & 31 \\
\hline Full length Pants & \\
\hline
\end{tabular}




\begin{tabular}{|l|c|}
\hline Any other type & 2 \\
\hline Types of Clothes Worn at Workplace & \\
\hline Full Sleeves & 44 \\
\hline Half Sleeves & 36 \\
\hline Sleeveless & 6 \\
\hline Shorts & 2 \\
\hline Full length Pants & 36 \\
\hline Any other type & 1 \\
\hline
\end{tabular}

Maximum (54\%) of study population experience most mosquito bites at night $1 \%$ of study population experience most mosquito bites in early morning. $37 \%$ of the study population use Bed Nets to prevent mosquito bites followed by Coils (31\%) and Screening of Windows and Doors (29\%). 3\% of the study population not use any type of preventive measure. $34 \%$ of the study population wear clothes such that their body surface is completely covered at home. 80\% of study population wear clothes such that their body surface is completely covered at work place.
In this study $77 \%$ of study population have water tank at home, $71 \%$ of study population has Covered Overhead Tank. 3\% of study population has Uncovered Overhead Tank. $71 \%$ of study population has Covered Underground Tank. $1 \%$ of study population have Uncovered Underground Tank and 54\% of study population cleans their water tank within 1 month. $85 \%$ of study population use Water Coolers in summer season and clean water coolers after summer.

Table 6: Response on knowledge assessment of study population regarding Malaria, Dengue and Chikungunya

\begin{tabular}{|c|c|c|}
\hline & $\begin{array}{l}\text { Frequency } \\
(\mathbf{n}=\mathbf{3 0 0})\end{array}$ & Percentage \\
\hline \multicolumn{3}{|c|}{$\begin{array}{l}\text { People having knowledge about symptoms of Malaria, Dengue and } \\
\text { Chikungunya }\end{array}$} \\
\hline Yes & 182 & 61 \\
\hline No & 118 & 39 \\
\hline \multicolumn{3}{|l|}{ Approach preferred for Fever Management } \\
\hline Self treatment by Paracetamol & 26 & 8.67 \\
\hline $\begin{array}{l}\text { Visit Doctor (Ayurvedic or Homeopathic } \\
\text { treatment - 26) }\end{array}$ & 186 & 62 \\
\hline Home based treatment & 10 & 3.33 \\
\hline Do not take any treatment & 78 & 26 \\
\hline \multicolumn{3}{|c|}{$\begin{array}{l}\text { Knowledge about "malaria mosquito bites early morning and } \\
\text { evening" }\end{array}$} \\
\hline Yes & 92 & 31 \\
\hline No & 208 & 69 \\
\hline \multicolumn{3}{|c|}{$\begin{array}{l}\text { Knowledge about "Dengue \& Chikungunya causing mosquito bites } \\
\text { during day }\end{array}$} \\
\hline Yes & 74 & 25 \\
\hline No & 226 & 75 \\
\hline \multicolumn{3}{|c|}{$\begin{array}{l}\text { Knowledge about "Suffering 2nd time from dengue can be } \\
\text { hazardous" }\end{array}$} \\
\hline Yes & 52 & 17 \\
\hline No & 248 & 83 \\
\hline
\end{tabular}

$61 \%$ of study population has knowledge about symptoms. $87 \%$ of the study population visit doctor for Fever treatment. $69 \%$ of study population is unaware that malaria causing mosquito bites early morning and evening.
$75 \%$ of the study population is unaware that Dengue and Chikungunya causing mosquito bites during day time. $83 \%$ of the study population is unaware that suffering from Dengue 2nd time can be hazardous. 
Table 7: Association of Education with Various Factors

\begin{tabular}{|c|c|c|c|c|}
\hline S. $\mathbf{N}$. & $\begin{array}{l}\text { Association of Education with Various } \\
\text { Factors }\end{array}$ & Chi Square & P Value & Significance \\
\hline 1. & $\begin{array}{l}\text { Suffered from Malaria, Dengue or } \\
\text { Chikungunya }\end{array}$ & 4.319 & 0.229 & Not Significant \\
\hline 2. & $\begin{array}{l}\text { Stagnant water source in and around } \\
\text { house }\end{array}$ & 6.412 & 0.093 & Not Significant \\
\hline 3. & Sewage water collection around house & 6.412 & 0.076 & Not Significant \\
\hline 4. & Measures taken to prevent Mosquito bite & 8.015 & 0.018 & Significant \\
\hline 5. & Water tank at home & 3.769 & 0.288 & Not Significant \\
\hline 6. & Fumigation in colony & 6.522 & 0.089 & Not Significant \\
\hline 7. & Indoor Residual Spray & 1.894 & 0.595 & Not Significant \\
\hline 8. & Symptom Knowledge & 11.776 & 0.008 & Significant \\
\hline 9. & Fever Management & 0.297 & 0.961 & Not Significant \\
\hline 10. & $\begin{array}{l}\text { Do you know Malaria Mosquito bites } \\
\text { early morning and evening? }\end{array}$ & 1.248 & 0.741 & Not Significant \\
\hline 11. & $\begin{array}{l}\text { Do you know Dengue and Chikungunya } \\
\text { Mosquito bites during day? }\end{array}$ & 5.482 & 0.14 & Not Significant \\
\hline 12. & $\begin{array}{l}\text { Suffering second time from Dengue can } \\
\text { be hazardous }\end{array}$ & 10.348 & 0.016 & Significant \\
\hline
\end{tabular}

Measures taken to prevent mosquito bite, Symptom knowledge, and Knowledge of suffering second time with dengue can be hazardous has significant association with the education status of study population.

\section{Discussion}

It is an Observational Cross-sectional study carried out in a study population of 300 of Indore City to determine the cause of rising incidence of Mosquito borne diseases (Malaria, Dengue, Chikungunya) and to assess the knowledge and attitude to prevent these diseases in Indore city.

In present study Most of the population has been found to reside near stagnant water source (Sewage line, pits, tyres, coconut shells or plastic containers etc) which may have contributed to increase in incidence of mosquito borne infection. Most of the people either disagrees or doesn't know (73\%) that Malathion fumigation occurs in their colony or not, this may be due to inadequacy of Municipal Corporation and may have caused rise in incidence of mosquito borne infections. $74 \%$ didn't have indoor residual spray in their houses. Mosquito bites are experienced mostly during night and evening hours. 37\% people use Bed nets followed by Coils(31\%) and Screening of windows and doors $29 \%$ ) to prevent mosquito bites. $34 \%$ wear type of clothes which do not completely cover body surface at home, due to which they experience much higher number of mosquito bites and this may have led to increasing incidence of mosquito borne diseases and at workplace most of the people $(80 \%)$ wear clothes such that their body surface is completely covered. 54\% clean their water tank within 1 month and rest either delay or do not clean, which may have caused increased incidence of mosquito borne diseases. $61 \%$ have crude knowledge about the symptoms of Malaria, Dengue and Chikungunya and they visit doctor for treatment. Rest of the people because of lack of knowledge either delay the treatment or treat themselves with over the counter drugs. Most of the people are unaware that malaria causing mosquito bites early morning $\&$ evening, and Dengue \& chikungunya causing mosquito bites during day time and that suffering from dengue 2 nd time can be hazardous, due to which they may not take precautions to prevent another dengue virus infection.

Similar study conducted by Nanjesh $\mathrm{KS}$ et $\mathrm{al}^{7}$ stated that shows that $48.5 \%$ subjects said that health authorities hadn't come for active surveillance, $41.5 \%$ visit general practitioner for consulting on their health issues, $65 \%$ used mosquito coils for protective measures and $31 \%$ used mosquito nets. Also $43 \%$ of them favoured covering containers and $32 \%$ preferred scrubbing of water containers once a week for intradomestic antilarval activities.

Another study by Wasnik $\mathrm{S}$ et $\mathrm{al}^{8}{ }^{8}$ When asked about the breeding places of mosquitoes, $56.6 \%$ said that only water can be the source for breeding places of mosquitoes whereas $50(33.33 \%)$ said that along with water, cooler or AC, tyre, flower pots etc. can be source of water where breeding can take place. 15 participants don't know the answer for this asked question.

Study by Sreedevi et $\mathrm{al}^{9}$ stated that before intervention there was fair knowledge on diseases spread by mosquitoes, breeding places, and personal protective measures among the village volunteer. Usage of PPMs was improved after education intervention among both literates and illiterates. Another study on similar topic by Kantesh Shidaraddi et $\mathrm{al}^{10}$ shows in his results that The awareness regarding malaria $(24.5 \%)$, dengue $(15 \%)$ and Japanese encephalitis $(2.5 \%)$ were considerably low as compared to chikungunya (60\%). 
Over half of people $(50.2 \%)$, do not know the mode of transmission of these diseases. They were unaware of the breeding places $(96 \%)$ and resting habitat $(42.5 \%)$. The most common symptoms and the modality of diagnosis was known to very few of the respondents' i.e. $23 \%$ and $13 \%$ respectively. While, only $8 \%$ of the participant were unaware of control measures for mosquito control. The single test of proportion, Z-test showed highly significant knowledge level among the population.

With a larger sample size and greater time duration, it could have been possible to assess the attitude of large number of people towards mosquito control and their knowledge about mosquito borne diseases.

\section{Conclusion}

In present study we found that Measures taken to prevent mosquito bite, Symptom knowledge, and Knowledge of suffering second time with dengue can be hazardous has significant association with the education status of study population.

\section{Recommendations}

Based on present study following are the recommendations for decrease in mosquito borne diseases: Increase IEC activities through posters, radio, TV shows and advertisements, pamphlets to make people aware about mosquito control techniques. There will be Behaviour Change in people to adopt proper sanitation practices. Educating people about Dry Day (to reduce mosquito breeding). There is a need of encouraging people to follow good cleaning and sanitation practices in and around their houses.

\section{Conflict of Interest: Nil \\ Funding: Nil}

\section{References}

1. Vector-borne diseases, Report of an informal expert consultation.SEA-CD-300, SEARO, New Delhi, 2014. Available at: who.int/iris/handle/10665/ 206531 Vectorborne diseases.pdf. Accessed on 16 August 2016.

2. Government of India national vector borne disease control programme directorate general of health services ministry of health \& family welfare. National vector borne disease control programme annual report 2014-15. 22, New Delhi, India: NVBDCP;2016.

3. Dengue Cases and Deaths in the Country since 2010 National Vector Borne Disease Control Programme. Available at: http://nvbdcp.gov.in/den-cd.html. assessed on 20.3.2018

4. Vector-borne diseases Fact sheet October 2017. Available at: http://www.who.int/mediacentre/factsheets/fs387/en/. assessed on 30.10.2017

5. Sharma AK, Bhasin S, Chaturvedi S, Predictors of knowledge about malaria in India. J Vector Borne Dis 2007;44(3):189-97.

6. Joshi AB, Banjara MR. Malaria related knowledge, practices and behavior of people in Nepal. $\mathrm{J}$ Vector Borne Dis 2008;45:44-50
7. Nanjesh KS, Hegde R, Badiger S, Kiran KG. A study of mosquito borne diseases awareness, attitude and practices among the rural population in Karnataka, India. Int J Community Med Public Health 2017;4:4178-81.

8. Wasnik S, Mehta A. Awareness, knowledge and practices about mosquito borne diseases in patients of tertiary care hospital in Navi Mumbai. Int J Community Med Public Health 2017;4:3673-7.

9. Sreedevi A, Burru RV, Rao GV, Yalamanchili P, Subhaprada C, Kumari V, Kala S, Aruna MS. Study on awareness about vector borne diseases and education about preventive measures in rural field practice areas of Kurnool medical college, Kurnool. Int J Med Sci Public Health 2016;5:1803-1807

10. Kantesh Shidaraddi, Madhavi Gajula, Neelesh M. N, Geeta V. Bathija. An Insight into the Knowledge and Practises Concerning Mosquito Borne Diseases in Urban Slums of old Hubli. Journal of Evolution of Medical and Dental Sciences 2015;4(18):P.3093-3100. 